\title{
Endoscopic Diagnosis of Gastric Peptic Ulcer Penetrating into the Liver
}

\author{
F. J. Jiménez-Pérez and M. A. Muñoz-Navas \\ Endoscopy Unit - Clínica Universitaria Navarra, Pamplona, Spain \\ Avenida Pio XII, 36, E-31080 Pamplona, Spain
}

\section{SUMMARY}

A 61-year-old man was admitted with upper gastrointestinal bleeding. Endoscopy showed a large gastric peptic ulcer with a pseudotumoral mass protruding from the ulcer bed. Histological examination of biopsies taken from the mass revealed distorted hepatic tissue and inflammatory changes. Hepatic penetration was diagnosed as the cause of bleeding. Surgery findings confirmed the endoscopic diagnosis.

\section{KEY WORDS}

Pepticulcer; Gastrointestinal bleeding; Ulcer penetration.

\section{INTRODUCTION}

Penetration of a peptic ulcer connotes a confined perforation into an adjacent structure (1). Clinically, the penetration usually intensifies the symptoms of the ulcer itself, but only seldom causes new symptoms referable to the involved organs (6).

Penetration into the liver is less frequent than those into other organs, and may lead to unusual complications such as abscess formation or upper gastrointestinal hemorrhage (5).

We report on a patient who presented with upper gastrointestinal bleeding due to a gastric ulcer penetrating into the liver.

\section{CASE REPORT}

A 61-year-old male alcoholic was hospitalized for upper gastrointestinal bleeding (melena) of three weeks' duration. There was no previous history of peptic ulcer disease. 
Physical examination revealed pronounced pallor, liver enlargement, maleolar edema and painful tenderness in the epigastrium. Blood pressure was $90 / 60 \mathrm{~mm} \mathrm{Hg}$, and pulse rate 110 per minute. The rest of the examination findings were unremarkable.

Laboratory evaluation showed severe hypochromic-microcytic anemia $(\mathrm{Hb}=6.9 \mathrm{~g} / \mathrm{dl})$, hypalbuminemia and leukocytosis (WBC 17.600). Liver function tests were within normal limits.

Emergency gastroscopy revealed a giant ulcer of about $5 \mathrm{~cm}$ diameter involving the lesser curvature of the gastric body. A pseudotumoral mass protruded from the central area of the ulcer bed. This lesion had the size of a table-tennis ball, was smooth with a reddish surface, and was tender when pressed with the biopsy forceps. The edges of the ulcer were covered with fibrin and clotted material, but there was no evidence of active bleeding (Fig. 1). Esophageal varices were not seen. Biopsies were taken separately from the ulcer margins and the pseudotumoral mass.

Microscopically, biopsies revealed inflammed gastric mucosa and several fragments of distorted liver tissue with areas of necrosis, acute inflammation and the presence of a small lumen resembling a biliary canaliculus containing bile thrombi (Fig. 2).

Surgery revealed a large gastric ulcer penetrating into the left lobe of the liver, and several neoplastic nodes involving both lobes. Histological examination of one of these nodes was consistent with the diagnosis of a metastasic lesion of an anaplastic lung cancer. It was afterwards confirmed by total body C. T. and lung tumor cytology.

Patient recovery was good after surgery, and he was transferred to the Oncology Department for treatment of his neoplastic disease.

\section{DISCUSSION}

We are aware of very few previous case reports of a gastric peptic ulcer penetrating into the liver in which the tissue diagnosis of this penetration was made in endoscopic biopsy material $(2,3,7)$. While in our patient gastroscopy revealed a pseudotumoral mass which made us suspect hepatic penetration, in other cases the ulcer itself is the only endoscopic finding (3). In such cases, diagnosis is achieved if biopsies of the base of the ulcer are deep enough to reach the possibly involved extragastric organ.

The hepatic histological changes found in our patient are consistent with those reported by others, designated as peptic hepatitis (3), and are the result of advanced peptic ulcer digestion. This local hepatic inflammation does not cause abnormalities in liver function tests.

Although a case of hepatocellular carcinoma presenting with bleeding due to duodenal perforation by the tumor has been reported (4), we consider that the presence of metastatic nodes from an anaplastic lung cancer did not play any role in the case we describe, as the area of the liver affected by the penetrating ulcer was free of tumoral nodes. 
In conclusion, we report an unusual cause of gastrointestinal bleeding which clinically is not readily suspected but which can be diagnosed by a combined endoscopic and histological examination prior to surgery.

\section{REFERENCES}

1. Bockus, H. L. (ed): Gastroenterology. 7th Ed. 4 Vols., Saunders, Philadelphia (1985)

2. Goldman, I. S.: Endoscopic diagnosis of hepatic penetration into a gastric ulcer. Am. J. Gastroenterol. 83 (1988) 589

3. Guerreri, C., M. Waxman: Hepatic tissue in gastroscopic biopsy: evidence of hepatic penetration by peptic ulcer. Am. J. Gastroenterol. 82 (1987) 890

4. Humbert, P., J. Sarmiento, J. Boix et al.: Hepatocellular carcinoma presenting with bleeding due to duodenal perforation by the tumor. Endoscopy 19 (1987) 37

5. Jiménez, A., J. Ortiz, A. Valcarreres et al.: Perforación gastroduodenal en 148 enfermos. I. Aspectos etiológicos, clínicos y diagnósticos. Rev. Esp. Enf. Ap. Digest. 73 (1988) 43

6. Joffe, N., D. A. Antonioli: Penetration into spleen by benign gastric ulcers. Clin. Radiol. 32 (1981) 177

7. Park, R. H., R. I. Rusell: Liver penetration by peptic ulcer. Am. J. Gastroenterol. 83 (1988) 793 


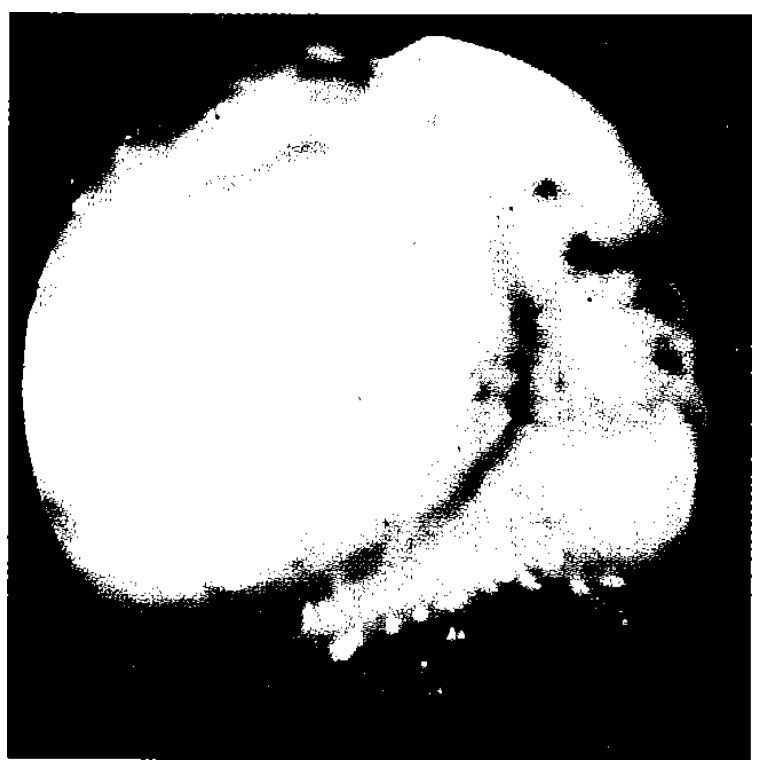

Figure 1. Pseudo-tumoral mass protruding from the ulcer bed secondary to hepatic penetration

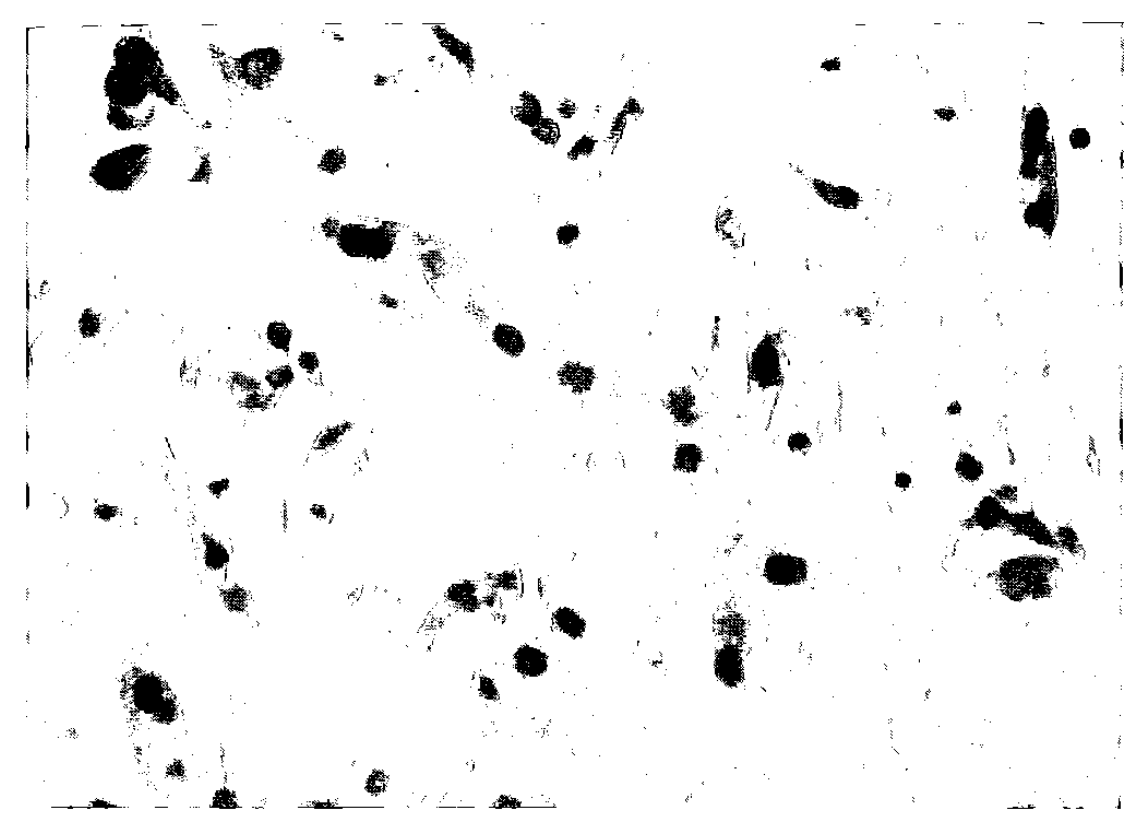

Figure 2. Distorted hepatic tissue in biopsies taken from the pseudo-tumoral mass 